\title{
A Parametric Study of the Evaporation Behaviour of UWS Droplets
}

\author{
Surendran Mikhil ${ }^{* 1}$, Shamit Bakshi ${ }^{1}$, Anand T.N.C. ${ }^{1,2}$ \\ ${ }^{1}$ Mechanical Engineering Dept., IIT Madras, Chennai, India \\ ${ }^{2}$ Mechanical Engineering Dept., IIT Palakkad, Palakkad, Kerala, India \\ *Corresponding author email: mikhilsuren@gmail.com
}

\begin{abstract}
A parametric computational study was conducted on UWS (urea-water-solution) droplets evaporating at conditions typical of an automobile SCR (selective catalytic reduction) system. The computational model used in the present work has been validated earlier using experimental data, and was found capable of predicting the evaporation behaviour of UWS droplets. The ambient temperatures considered in the present study ranged from $423 \mathrm{~K}$ to 873 $\mathrm{K}$, and the free-stream gas velocities used were between $1 \mathrm{~m} / \mathrm{s}$ and $100 \mathrm{~m} / \mathrm{s}$. The droplets were injected perpendicular to the free-stream, and the droplet diameter, as well as its position, was tracked with time. The initial diameters of the droplets investigated ranged between 10 and 200 microns. A rapid mixing (RM) model was employed for the liquid phase in order to reduce the computational costs, and the droplet evaporation model was based on the vaporization model proposed by Abramzon and Sirignano. The effect of the ambient gas, on the vaporization rate of the droplet, was also investigated in the present work. The governing equations, used in the computational model, were solved numerically using MATLAB, and the results on the vaporization behaviour of the UWS droplets are presented.
\end{abstract}

\section{Keywords}

Selective Catalytic Reduction, Urea Water Solution, Droplet Evaporation

\section{Introduction}

Urea-based selective catalytic reduction (SCR) is one of the most promising after-treatment techniques used in the automobile industry to attain very low levels of NOx gas emissions from automobile diesel engines. In this technique, a solution of urea in water is injected into the exhaust gas of the engine and is allowed to undergo thermal decomposition to produce ammonia, which acts as the required reducing agent. Evaporation of the droplets of ureawater-solution (UWS) is one of the critical steps in the ammonia generation process, and has been an important topic of research in the past 15 years.

Experiments on UWS droplets have revealed that the evaporation behaviour of these droplets can be divided into different stages [1-4]. Water alone evaporates during the first stage of evaporation, leading to a gradual increase of the mass fraction of urea within the droplet. Preferential evaporation of water from the surface of the droplet leads to the formation of a urea-rich shell, and it is believed that urea evaporates from the surface when the droplet surface temperature reaches values above its melting point $(406 \mathrm{~K})$. While the first stage of evaporation of UWS droplets has always been observed to be in accordance to the $d^{2}$ law of evaporation, the later stages have been reported to be temperature dependent. Urea crystallization has been observed at ambient temperatures below $406 \mathrm{~K}$, gradual evaporation has been observed at temperatures of $423 \mathrm{~K}$ and $473 \mathrm{~K}$, and micro-explosions have been observed when the ambient temperatures were greater than or equal to $523 \mathrm{~K} \mathrm{[4].}$

Even though the vaporization behaviour of UWS droplets is complex, simple evaporation models have been employed by researchers to predict their evaporation behaviour and to estimate the vaporization rates [5-9]. The use of a rapid mixing model for the liquid phase of the UWS droplet has been found to be reasonably accurate in predicting the droplet diameter and temperature histories [5,6]. Modeling the depletion of urea as a vaporization process has 
also been reported to be better-suited for the prediction of urea depletion rates as compared to the thermal dissociation approach [5]. A review of these literature also shows that different correlations and sub-models have been used by researchers in order to estimate important thermal and physical properties of urea, water and UWS. This in turn may have a significant influence on the predicted vaporization rates. A recent numerical study performed by us, tested the efficacy of various sub-models and correlations available in literature by comparing the results predicted by the model with experimental data on UWS droplets evaporating under well-defined forced convective conditions [4,9]. The findings from this comparative study were eventually used to develop a numerical model capable of predicting the evaporation behaviour of UWS droplets with reasonable accuracy [9]. In the present work, we have used the same computational model to perform a parametric study on UWS droplets evaporating under conditions typical of an automobile SCR system. Important aspects of this computational model have been explained in the next section.

\section{Computational Model for Evaporating UWS Droplets}

The computational model used in this study was based on the droplet vaporization model proposed by Abramzon and Sirignano [10]. This single component model was adapted to simulate UWS droplets by considering UWS as a bicomponent liquid. The droplet was assumed to be stationary, and placed in a hot stream of nitrogen gas, flowing at a steady velocity. The rapid mixing model was used for the liquid phase of the droplet, leading to a uniform distribution of temperature and urea concentration throughout the droplet. Urea was always assumed to be in a dissolved state. While this could lead to conditions of oversaturation, the probability of precipitation and agglomeration of urea crystals were not considered in the model. Simultaneous evaporation of water and urea was allowed, and the depletion of urea, which was treated as a vaporization process, was considered as soon as the droplet temperature reached the melting point of urea. The saturation vapor pressure for urea was estimated using the correlation reported by Ebrahimian et al. [8], and the partial pressures of the vapours of water and urea were estimated using an NRTL model [8]. The density and vaporization enthalpy of molten urea were also treated as functions of the droplet temperature. The dissociation energy of urea was not added to its vaporization enthalpy, as it was found to lead to a considerable underprediction of the vaporization rates. Details of the equations used in this model, as well as the solution procedure has been explained in detail in literature [9].

During the course of the work presented here, the following changes were made to the abovementioned computational model [9].

1) The composition of the ambient gas was changed from pure nitrogen to that of a gas mixture consisting of nitrogen (67\%), carbon dioxide (12.5\%), water vapor $(11 \%)$, and oxygen $(9.5 \%)$, which is comparable with the exhaust gas composition of a typical automobile diesel engine.

2) The droplets were injected perpendicular to the gas flow (Figure 1), and were no longer assumed to be stationary with respect to the gas flow. This was done so as to be able to better simulate the conditions that exist in an SCR system. The coefficient of drag on the droplet was estimated using the equation reported by Abramzon and Sirignano [10], and the instantaneous droplet velocities were evaluated by performing a force balance along the $X$ and $Y$ directions.

With these modifications made to the boundary conditions of the droplet, a parametric study was performed on evaporating UWS droplets. The parameters considered in this study were 
the initial diameter of the droplet, the temperature and velocity of the ambient gas, and the initial droplet velocity. Droplet breakup was not considered in the present study even though the initial Weber numbers were sometimes large enough to cause secondary atomization. The results obtained from this parametric study are explained in the next section.

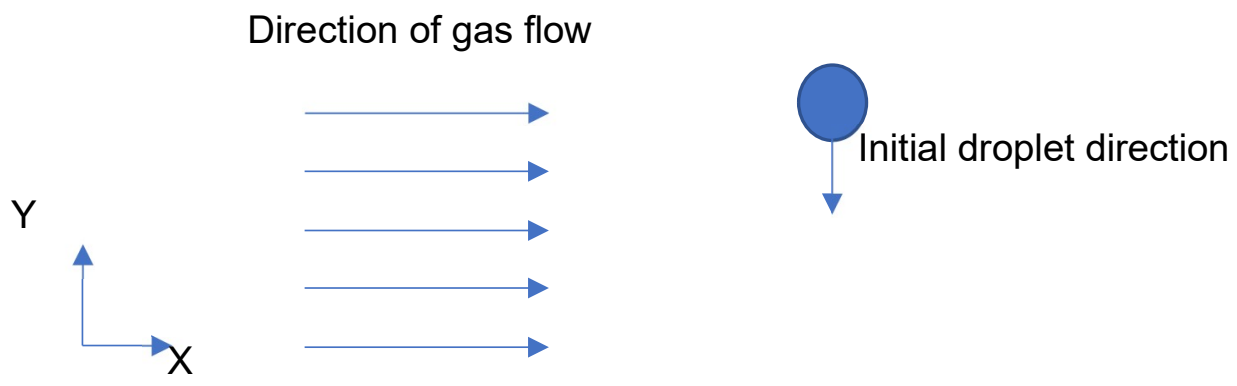

Figure 1. Schematic of the flow configuration.

\section{Results and Discussion}

Predicted Evaporation Behaviour of UWS droplets:

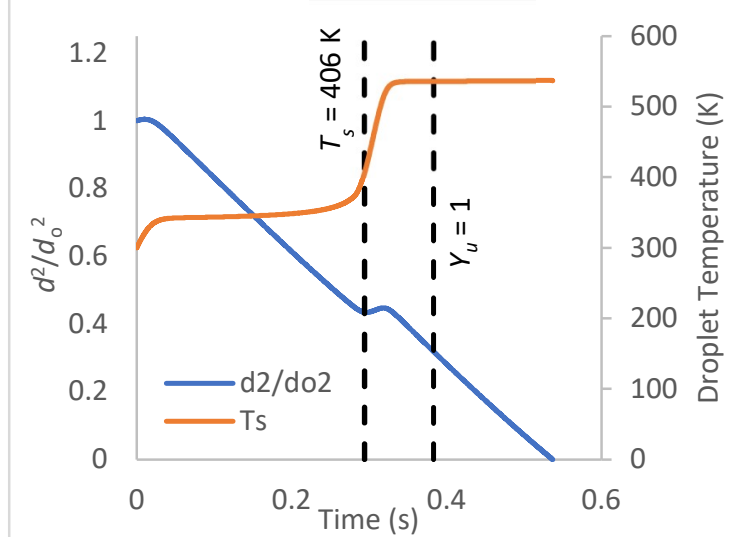

(a)

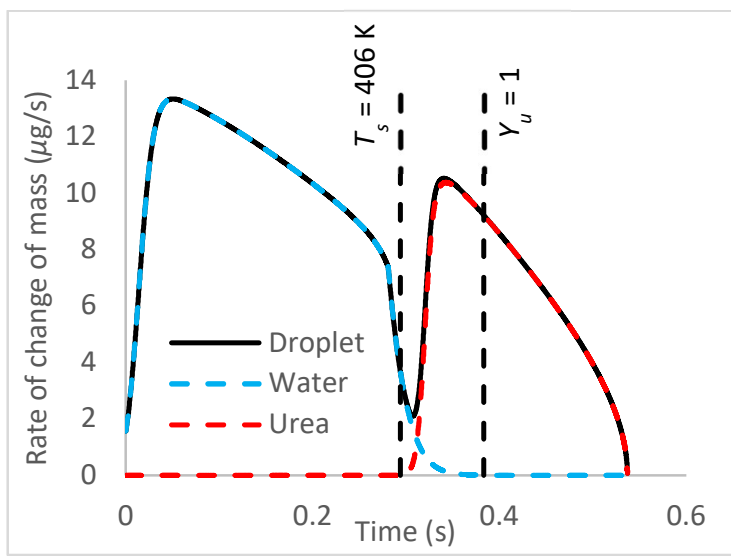

(b)

Figure 2. Sample plots showing the predicted evaporation behaviour of UWS droplets. (a) Droplet temperature and normalized diameter histories (b) Rate of change of mass vs. time. (Initial droplet diameter $=200 \mu \mathrm{m}$, Ambient gas temperature $=873 \mathrm{~K}$, Ambient gas velocity $=1 \mathrm{~m} / \mathrm{s}$ and Initial droplet velocity $=0 \mathrm{~m} / \mathrm{s}$ )

Sample plots showing the characteristic predicted evaporation behaviour of a UWS droplet are given in Figure 2. Even though the experimentally observed behaviour of an evaporating UWS droplet is dependent on the ambient temperature, our simplified computational model, which uses the rapid mixing model for the liquid phase, predicts the droplet to undergo two distinct stages (seen in Figure 2 (a)) of evaporation under all temperature conditions. Water alone evaporates during the first stage of evaporation, whereas urea evaporates during the later stages along with the residual water that is retained in the droplet. As can be seen from Figure 2 (b), urea vaporization is evaluated as soon as the droplet temperature $\left(T_{s}\right)$ reaches the melting point of urea, and complete evaporation of water is not assumed to be a necessary condition for the start of vaporization of urea.

The temperature history (seen in Figure 2 (a)) of the UWS droplet can be divided into four stages. The first stage characterizes the transient heating of the droplet. This is then followed by a stage of almost constant temperature characterizing the evaporation of water. A steep increase in droplet temperature is observed towards the end of this phase, which is finally followed by a constant temperature stage corresponding to the evaporation of molten urea. 
Effect of ambient temperature on the predicted droplet lifetime:
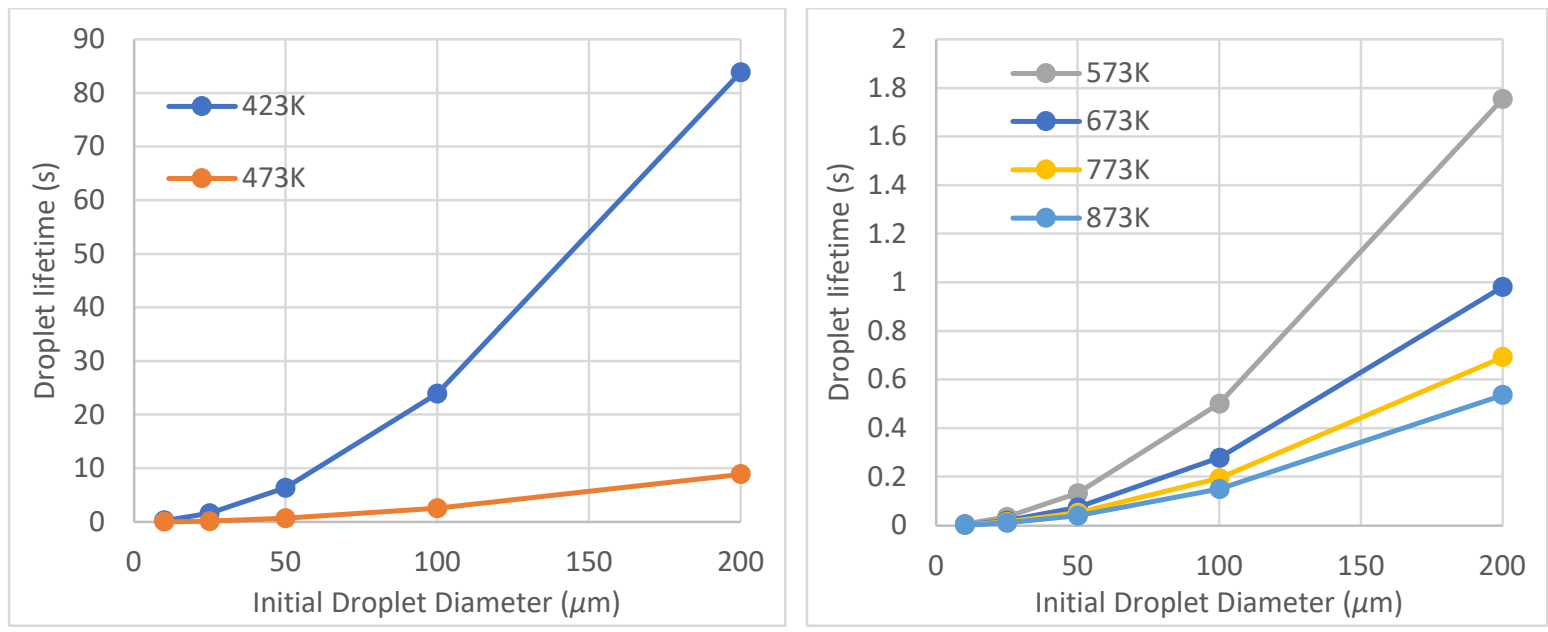

Figure 3. Effect of ambient gas temperature on the total lifetime of the UWS droplet (Initial droplet diameter ranging from $10 \mu \mathrm{m}$ to $200 \mu \mathrm{m}$, Ambient gas temperature ranging from $423 \mathrm{~K}$ to $873 \mathrm{~K}$, Ambient gas velocity $=1$ $\mathrm{m} / \mathrm{s}$ and Initial droplet velocity $=0 \mathrm{~m} / \mathrm{s}$ )

Figure 3 and Table 1 show the effect of the temperature of the ambient gas on the total lifetime of an evaporating UWS droplet. As can be seen, the total lifetime of a UWS droplet is a strong function of the ambient gas temperature. The predicted droplet lifetimes of a $200 \mu \mathrm{m}$ droplet at ambient temperatures $423 \mathrm{~K}$ and $873 \mathrm{~K}$ are $\sim 83.89$ and $\sim 0.54$ seconds respectively. The corresponding droplet lifetimes for a $10 \mu \mathrm{m}$ droplet are $\sim 0.26 \mathrm{~s}$ and $1.6 \mathrm{~ms}$ respectively.

Table 1 - Total lifetimes of evaporating UWS droplets at different ambient gas temperatures (Ambient gas velocity $=1 \mathrm{~m} / \mathrm{s}$ and Initial droplet velocity $=0 \mathrm{~m} / \mathrm{s}$ ).

\begin{tabular}{c|ccccc}
\hline \multirow{3}{*}{$\begin{array}{c}\text { Ambient Gas } \\
\text { Temperature (K) }\end{array}$} & \multicolumn{5}{|c}{ Initial diameter of the droplet $(\mu \mathrm{m})$} \\
\cline { 2 - 6 } & 10 & \multicolumn{5}{|c}{ Droplet lifetime $(\mathrm{s})$} \\
\hline 423 & 0.2561 & 1.6170 & 6.3423 & 23.950 & 83.890 \\
473 & 0.0271 & 0.1702 & 0.6675 & 2.5247 & 8.8921 \\
573 & 0.0055 & 0.0341 & 0.1330 & 0.5009 & 1.7552 \\
673 & 0.0030 & 0.0189 & 0.0738 & 0.2787 & 0.9817 \\
773 & 0.0021 & 0.0131 & 0.0513 & 0.1947 & 0.6922 \\
873 & 0.0016 & 0.0100 & 0.0393 & 0.1496 & 0.5369
\end{tabular}

Effect of ambient gas velocity on the predicted droplet lifetime:

Table 2 shows the effect of the ambient gas velocity on the total droplet lifetime. While the effect of the ambient gas velocity on the droplet lifetime appears to be negligible at temperatures up to $473 \mathrm{~K}$, there appears to be a slight reduction in droplet lifetimes when the temperature is greater than or equal to $573 \mathrm{~K}$. At low temperatures, owing to the low vaporization rates, droplets attain free stream velocities instantaneously compared to their total droplet lifetimes (as seen in Figure 4), thereby leading to zero relative velocities during most of their lifetime, irrespective of the actual ambient gas velocity. However, at higher temperatures, the droplet takes a considerable portion of its total lifetime to attain the freestream velocity, which in turn causes the ambient gas velocity to have an effect on the droplet lifetime. 
Table 2 - The effect of the ambient gas velocity on the total lifetime of evaporating UWS droplets (Initial droplet velocity $=0 \mathrm{~m} / \mathrm{s}$ ).

\begin{tabular}{c|cccc}
\hline \multirow{3}{*}{$\begin{array}{c}\text { Ambient Gas } \\
\text { Temperature }(K)\end{array}$} & \multicolumn{3}{|c}{$\mathrm{d}_{0}=10 \mu \mathrm{m}$} & \multicolumn{3}{c}{$\mathrm{d}_{0}=200 \mu \mathrm{m}$} \\
\cline { 2 - 5 } & $1 \mathrm{~m} / \mathrm{s}$ & $100 \mathrm{~m} / \mathrm{s}$ & $1 \mathrm{~m} / \mathrm{s}$ & $100 \mathrm{~m} / \mathrm{s}$ \\
\cline { 2 - 5 } & \multicolumn{4}{|c}{ Total droplet lifetime (s) } \\
\cline { 2 - 5 } & 0.2561 & 0.2556 & 83.890 & 83.756 \\
473 & 0.0271 & 0.0266 & 8.8921 & 8.7602 \\
573 & 0.0055 & 0.0051 & 1.7552 & 1.6297 \\
673 & 0.0030 & 0.0027 & 0.9817 & 0.8635 \\
773 & 0.0021 & 0.0019 & 0.6922 & 0.5814 \\
873 & 0.0016 & 0.0014 & 0.5369 & 0.4334
\end{tabular}

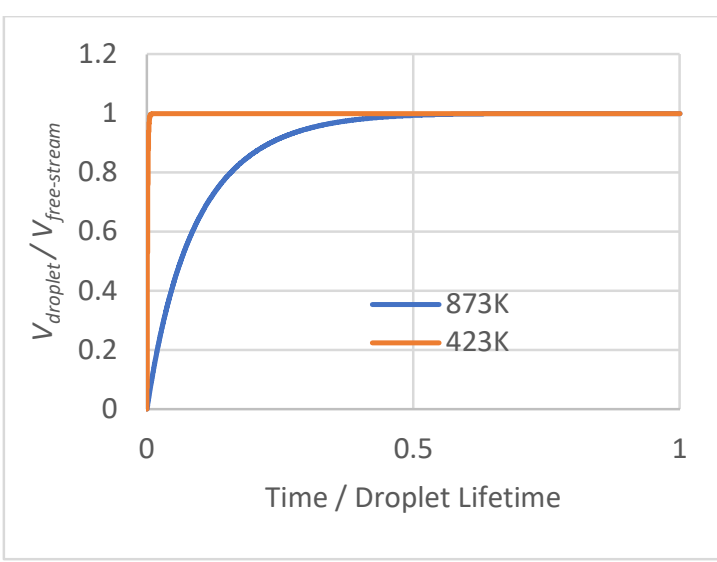

(a)

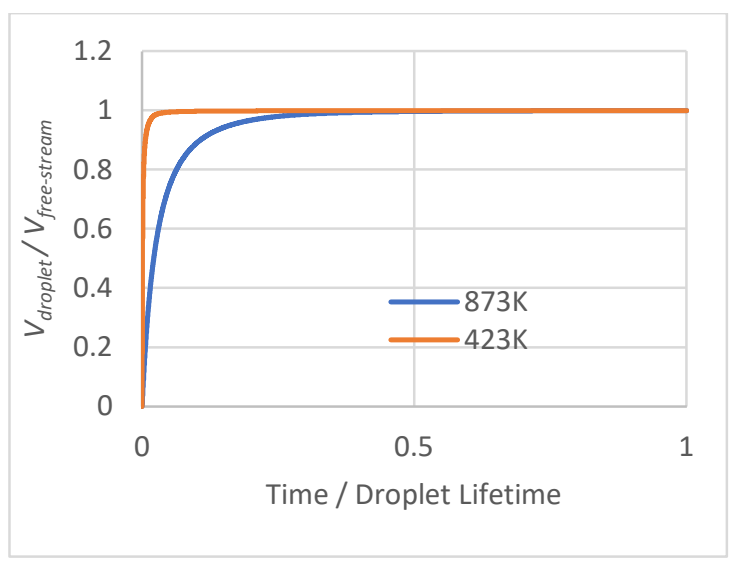

(b)

Figure 4. Time taken by the droplet to attain free-stream velocity as a ratio of its total lifetime. (a) Initial droplet diameter $=10 \mu \mathrm{m}(\mathrm{b})$ Initial droplet diameter $=200 \mu \mathrm{m}$

Effect of initial droplet velocity on the predicted droplet lifetime:

The effect of the initial droplet velocity perpendicular to the flow is similar to the effect of the ambient gas velocity (as seen from Table 3). At low temperatures, the effect is non-existent, where as at higher temperatures there appears to be a marginal effect.

Table 3 - The effect of the initial droplet velocity on the total lifetime of evaporating UWS droplets (Ambient gas velocity $=100 \mathrm{~m} / \mathrm{s}$ )

\begin{tabular}{c|cccc}
\hline \multirow{3}{*}{$\begin{array}{c}\text { Ambient Gas } \\
\text { Temperature }(K)\end{array}$} & \multicolumn{3}{|c}{$\mathrm{d}_{0}=10 \mu \mathrm{m}$} & \multicolumn{3}{c}{$\mathrm{d}_{0}=200 \mu \mathrm{m}$} \\
\cline { 2 - 5 } & $0 \mathrm{~m} / \mathrm{s}$ & $40 \mathrm{~m} / \mathrm{s}$ & $0 \mathrm{~m} / \mathrm{s}$ & $40 \mathrm{~m} / \mathrm{s}$ \\
\cline { 2 - 5 } & \multicolumn{4}{|c}{ Total droplet lifetime (s) } \\
\cline { 2 - 5 } & 0.2556 & 0.2554 & 83.756 & 83.709 \\
423 & 0.0266 & 0.0265 & 8.7602 & 8.7150 \\
573 & 0.0051 & 0.0050 & 1.6297 & 1.5883 \\
673 & 0.0027 & 0.0027 & 0.8635 & 0.8260 \\
773 & 0.0019 & 0.0018 & 0.5814 & 0.5477 \\
873 & 0.0014 & 0.0013 & 0.4334 & 0.4034
\end{tabular}


Effect of ambient gas composition on the predicted droplet lifetime:

Two different ambient gas compositions were used to test the effect of the composition of the ambient gas on the droplet vaporization rate; pure nitrogen, and an exhaust gas mixture of nitrogen (67\%), carbon dioxide (12.5\%), water vapor (11\%), and oxygen (9.5\%). The results are shown in Figure 5. As can be seen, the ambient gas used while simulating droplet evaporation, can potentially have a considerable effect on the predicted droplet lifetimes. When pure nitrogen was used as the ambient gas, instead of a typical exhaust gas mixture, the predicted droplet lifetimes, at an ambient gas temperature of $873 \mathrm{~K}$, were observed to be higher by $\sim 10 \%$.

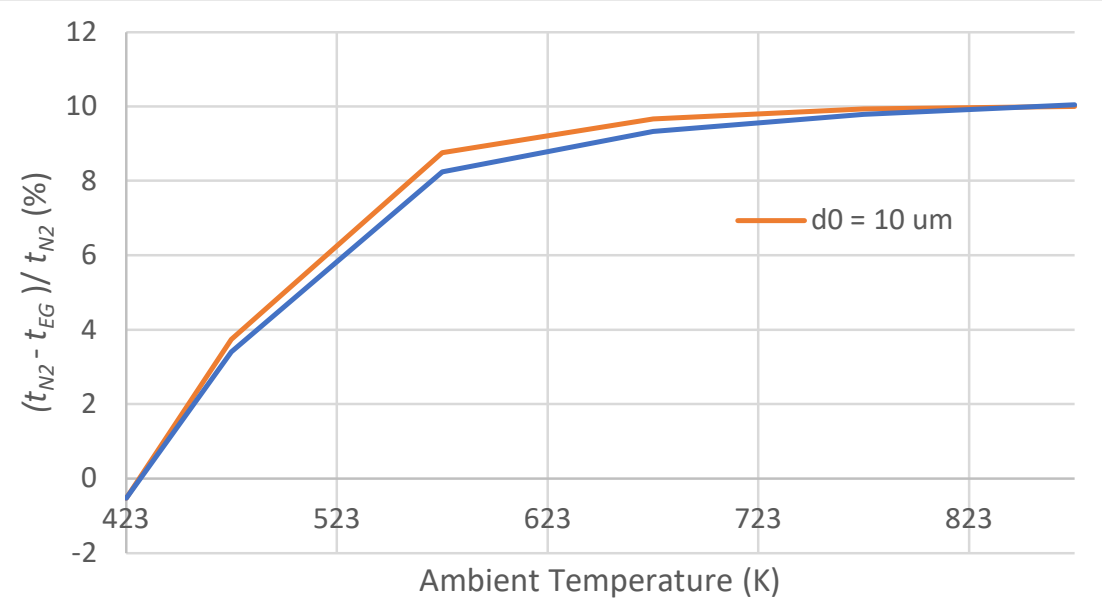

Figure 5. Percentage difference in the predicted droplet lifetimes with nitrogen $\left(t_{N 2}\right)$ and an exhaust gas mixture $\left(t_{E G}\right)$ used as the ambient gas. (Ambient gas velocity $=100 \mathrm{~m} / \mathrm{s}$ and Initial droplet velocity $=0 \mathrm{~m} / \mathrm{s}$ ).

Effect of droplet and gas velocities on the predicted droplet displacements:

Table 4 and Table 5 show the maximum droplet displacements along the $X$ and $Y$ directions considering different droplet and gas velocities. Since the droplets attain velocities equal to the free stream velocities rather quickly, the maximum displacement of a droplet along the $X$ direction $\left(X_{\max }\right)$ is approximately equal to the product of the droplet lifetime and the free-stream velocity. The maximum $Y$ displacement $\left(Y_{\max }\right)$ for a droplet with initial diameter $10 \mu \mathrm{m}$ is negligibly small, where as those for larger droplets can be significantly high, especially when the relative velocity of the droplet with respect to the gas is low.

Table 4 - Maximum displacement (in centimetres) along the $X$ and $Y$ directions for a droplet of initial diameter 10 $\mu \mathrm{m}$.

\begin{tabular}{c|cccc}
\hline \multirow{2}{*}{$\begin{array}{c}\text { Ambient Gas } \\
\text { Temperature }(\mathrm{K})\end{array}$} & \multicolumn{3}{|c}{$V_{\text {free-stream }}=1 \mathrm{~m} / \mathrm{s}$} & \multicolumn{3}{c}{$V_{\text {free-stream }}=100 \mathrm{~m} / \mathrm{s}$} \\
\cline { 2 - 5 } & $0 \mathrm{~m} / \mathrm{s}$ & $0 \mathrm{~m} / \mathrm{s}$ & $0 \mathrm{~m} / \mathrm{s}$ & $40 \mathrm{~m} / \mathrm{s}$ \\
\cline { 2 - 5 } & $X_{\max }$ & $Y_{\max }$ & $X_{\max }$ & $Y_{\max }$ \\
\hline 423 & 25.58 & 0.0190 & 2554.76 & 1.14 \\
473 & 2.68 & 0.0029 & 264.86 & 1.11 \\
573 & 0.52 & 0.0011 & 49.67 & 1.07 \\
673 & 0.28 & 0.0008 & 26.06 & 1.04 \\
773 & 0.19 & 0.0006 & 17.29 & 0.99 \\
873 & 0.14 & 0.0005 & 12.70 & 0.95
\end{tabular}


Table 5 - Maximum displacement (in metres) along the $X$ and $Y$ directions for a droplet of initial diameter 200 $\mu \mathrm{m}$.

\begin{tabular}{c|cccc}
\hline \multirow{2}{*}{$\begin{array}{c}\text { Ambient Gas } \\
\text { Temperature (K) }\end{array}$} & \multicolumn{3}{|c}{$V_{\text {free-stream }}=1 \mathrm{~m} / \mathrm{s}$} & $V_{\text {free-stream }}=100 \mathrm{~m} / \mathrm{s}$ \\
\cline { 2 - 5 } & $0 \mathrm{~m} / \mathrm{s}$ & $0 \mathrm{~m} / \mathrm{s}$ & $0 \mathrm{~m} / \mathrm{s}$ & $40 \mathrm{~m} / \mathrm{s}$ \\
\cline { 2 - 5 } & $X_{\max }$ & $Y_{\max }$ & $X_{\max }$ & $Y_{\max }$ \\
\hline 423 & 83.6 & 18.6 & 8373.8 & 19.7 \\
473 & 86.9 & 2.27 & 874.2 & 3.38 \\
573 & 1.59 & 0.62 & 161.1 & 1.80 \\
673 & 0.85 & 0.38 & 84.5 & 1.60 \\
773 & 0.57 & 0.27 & 56.3 & 1.52 \\
873 & 0.43 & 0.21 & 41.1 & 1.48
\end{tabular}

\section{Conclusions}

A parametric study was performed on evaporating UWS droplets using a bicomponent droplet evaporation model. The effect of various parameters such as the ambient gas temperature, gas velocity, initial droplet size, initial droplet velocity and the composition of the ambient gas on the predicted droplet lifetimes was studied, and the observations are as follows.

1) Ambient gas temperature has a significant influence on the UWS droplet lifetime. While a $50 \mu \mathrm{m}$ droplet can take as much as $6.3 \mathrm{~s}$ to undergo complete evaporation when the ambient gas temperature is $423 \mathrm{~K}$, it takes only $\sim 0.04 \mathrm{~s}$ to do the same when the gas temperature is $873 \mathrm{~K}$.

2) Ambient gas velocity does not have a significant influence on the droplet lifetime. At low temperatures the effect is close to non-existent, whereas a small reduction in droplet lifetime was observed at temperatures above $573 \mathrm{~K}$. However, higher ambient gas velocities can cause proportionally higher droplet displacements along the flow direction.

3) The initial droplet velocity does not have a significant influence on the droplet lifetime, but can lead to higher droplet displacements.

4) The composition of the ambient gas selected during the simulation can affect the predicted droplet lifetimes, because of the differences in the values of their thermophysical properties. The droplet lifetimes predicted using pure nitrogen as the ambient gas, instead of an exhaust gas mixture, was found to be higher by $\sim 10 \%$.

\section{Nomenclature}

$d \quad$ droplet diameter $[\mu \mathrm{m}]$

$d_{0} \quad$ initial droplet diameter $[\mu \mathrm{m}]$

EG exhaust gas

N2 nitrogen

NRTL non-random two liquid

SCR Selective catalytic reduction

$t \quad$ droplet lifetime [s]

$T_{s} \quad$ droplet temperature $[\mathrm{K}]$

UWS urea-water-solution

$V \quad$ velocity $[\mathrm{m} / \mathrm{s}$ ]

$X_{\max }$ maximum droplet displacement along the $X$ direction [cm, $\mathrm{m}$ ]

$Y_{\max }$ maximum droplet displacement along the $Y$ direction [cm, $\mathrm{m}$ ]

$Y_{u} \quad$ urea mass fraction 


\section{References}

[1] Musa, S., M. Saito, T. Furuhata, and M. Arai, Aug. 27-1. 2006, 10th Internationl Conference on Liquid Atomization and Spray Systems (ICLASS).

[2] Wang, T. J., S. W. Baek, S. Y. Lee, D. H. Kang, and G. K. Yeo, 2009, AIChE Journal, 55 (12), pp. 3267-3276.

[3] Wei, L., Z. Youtong, and M. Asif, 2016, AIChE Journal, 62 (3), pp. 880-890.

[4] Surendran, M., T. N. C. Anand, and S. Bakshi, 2020, AIChE Journal, 66, pp. e16845

[5] Birkhold, F., U. Meingast, P. Wassermann, and O. Deutschmann, 2007, Applied Catalysis

B: Environmental, 70 (1-4), pp. 119-127

[6] Abu-Ramadan, E., K. Saha, and X. Li, 2011, AIChE Journal, 57 (11), pp. 3210-3225

[7] Lundström, A., B. Waldheim, H. Ström, and B. Westerberg, 2011, Proceedings of the Institution of Mechanical Engineers, Part D: Journal of Automobile Engineering, 225 (1), pp. 1392-1398

[8] Ebrahimian, V., A. Nicolle, and C. Habchi, 2012, AIChE Journal, 57 (8), pp. 1998-2009

[9] Mikhil, S., S. Bakshi and T.N.C. Anand, 2021, International Journal of Heat and Mass Transfer, 168, pp. 120878

[10] Abramzon B. and W. Sirignano, 1989, International Journal of Heat and Mass Transfer, 32 (9), pp. 1605-1618 